\title{
TECNOLOGIA DE INFORMAÇÃO E CUSTOMIZAÇÃO EM MASSA: EVIDÊNCIAS NA INDÚSTRIA DE TRANSFORMAÇÃO
}

\author{
Andre Gustavo Carvalho Machado \\ Doutor em Administração pela Universidade Federal de Pernambuco - UFPE \\ Professor da Universidade Federal de Pernambuco - UFPE \\ agcmachado@gmail.com
}

\section{Walter Fernando Araújo Moraes}

Doutor em Mangament Sciences pela University of Manchester Institute of Science and Technology UMIST

Professor da Universidade Federal de Pernambuco - UFPE

walter.moraes@ufpe.br

\section{RESUMO}

Estratégia de customização em massa pode ser entendida como o conjunto de planos que irá servir de referência para a tomada de decisões, no sentido de satisfazer às necessidades individuais dos clientes, por meio da rápida disponibilização de bens e serviços, a custos baixos e em grande escala. O objetivo deste artigo é analisar como a tecnologia de informação está sendo utilizada para habilitar a adoção da customização em massa. A estratégia de pesquisa adotada foi de estudo de casos múltiplos, empreendido em sete empresas pertencentes a diferentes setores da indústria de transformação. Entrevistas semiestruturadas foram adotadas como principal técnica para coleta de dados. A análise de dados ocorreu em dois estágios: análise individual e análise cruzada dos casos. Os resultados permitiram constatar que o uso da tecnologia de informação nos processos das empresas que customizam seus produtos em massa não se dá de maneira uniforme. Seu grau de utilização depende, principalmente, do estágio na cadeia de valor onde ocorre a customização e do modelo adotado para venda dos produtos e interação com os clientes. A pesquisa permitiu concluir que a interação e o acompanhamento do cliente, a busca pela flexibilidade nos processos produtivos, a maximização do projeto colaborativo e, em menor grau de utilização, a integração entre os elos da cadeia de suprimentos, são elementos suportados pela tecnologia de informação para a implementação da customização em massa.

Palavras-chave: Customização; Tecnologia de informação; Estratégia. 


\section{INTRODUÇÃO}

Customização em massa diz respeito à "habilidade de fabricar, rapidamente, uma diversidade de produtos customizados, em grande escala, e a custos comparáveis à produção em massa" (Qiang, Vonderembse, Ragu-Nathan, \& Ragu-Nathan, 2004, p. 152, tradução nossa). O interesse acadêmico pela customização em massa tem crescido ao longo dos anos. Por meio de uma pesquisa na base de dados ProQuest, verifica-se que na década de 1990 foram publicados, especificamente em revistas acadêmicas, 44 artigos cujo título contemplava este tema; na década de 2000, 150 artigos; e apenas entre os meses de janeiro de 2010 e janeiro de 2011, 21 artigos já tinham enfocado o termo customização em massa no título do documento.

Implementar esta abordagem, no entanto, representa um obstáculo a ser superado pelos gestores, que terão de habilitar seus processos produtivos para serem capazes de fabricar com velocidade produtos individualizados, obedecendo às especificações de qualidade e entregando no prazo exigido, com custos reduzidos.

O acelerado desenvolvimento de novas tecnologias, por seu turno, em conjunto com a utilização de modelos de gestão integrada e de novos métodos de fabricação, tem propiciado que as empresas contornem certos trade offs. Qualidade ou baixo custo, variedade ou volume de produção, eficiência ou customização são opções historicamente excludentes que, quando superadas, corroboram para que se atinjam níveis de desempenho superiores e acirrem ainda mais a concorrência nos mercados (Addis \& Holbrook, 2001; Davis, Aquilano, \& Chase, 2001; Shewchuk \& Moodie, 2000; Squire, Brown, Readman, \& Bessant, 2006).

Entre as empresas que decidiram adotar a customização em massa como estratégia para o alcance de vantagens competitivas, destacam-se a Dell, Hertz, Amazon.com, Nike, Adidas, Scania, Sears, Proctor e Gamble, entre outras (Piller \& Kumar, 2006). Neste contexto, o objetivo deste artigo é analisar como a tecnologia de informação (TI) está sendo utilizada para habilitar a adoção da customização em massa. Para isso, foram realizados estudos de casos em sete empresas pertencentes a diferentes setores da indústria de transformação, tais como: automobilístico, mecânico, químico, calçados, móveis e confecções de vestuário.

A razão da escolha pela indústria de transformação decorre do fato de que evidências colhidas na literatura sobre o tema sugerem que a customização em massa é mais comumente adotada em processos empresariais prioritariamente geradores de bens, por meio da transformação de insumos em produtos tangíveis (Duray, 2002; Duray, Ward, Milligan, \& Berry, 2000; Qiang et al., 2004; Qiang, Vonderembse, \& Ragu-Nathan, 2001).

Revista de Administração e Inovação, São Paulo, v. 8, n. 2, p.190-215, abr./jun. 2011 
A escassez de estudos, por sua vez, que conduzam a uma melhor compreensão de como as empresas brasileiras estão adotando tecnologias de informação em seus respectivos processos de customização em massa, considerando os desafios impostos pelas características do contexto nacional para a aplicação deste conceito, sugere a necessidade de pesquisas nesta área de conhecimento.

O trabalho foi estruturado da seguinte maneira: inicialmente será realizada uma breve fundamentação teórica a respeito da importância da tecnologia de informação para os objetivos da customização em massa. Logo após, são apresentados os procedimentos metodológicos adotados. Em seguida, é realizada uma análise individual dos casos estudados, procurando desvendar o papel da tecnologia de informação para o alcance dos propósitos de cada empresa. Com o intuito de identificar similaridades ou aspectos distintivos entre as empresas, além de diagnosticar os resultados sob a perspectiva da teoria que fundamenta a pesquisa, numa etapa seguinte, foram realizadas análises cruzadas dos casos. Por fim, são apresentadas as conclusões.

\section{CUSTOMIZAÇÃO EM MASSA E TECNOLOGIA DE INFORMAÇÃO}

A introdução da tecnologia de informação nos processos industriais e nas atividades empresariais como um todo tem sido um importante suporte para a conquista de vantagens competitivas. Os benefícios advêm, sobretudo, da melhoria dos aspectos operacionais e estratégicos da organização, em termos de confiabilidade de entrega, estabilidade dos processos, redução do time to market, velocidade e otimização do fluxo de informações e materiais, integração da cadeia de suprimentos, melhoria da qualidade, produtividade, flexibilidade, redução de custos, entrada em novos mercados, conquista de novos clientes e oferecimento de novos produtos.

Para uma empresa obter os benefícios decorrentes do uso da tecnologia, entretanto, é imprescindível o alinhamento da estratégia tecnológica com a de negócios, de modo que a primeira possa facilitar o desenvolvimento dos fatores fundamentais para o sucesso empresarial no ambiente em que se encontra inserida a organização. Como explicitou Porter (1991), a tecnologia pode influir na vantagem competitiva se tiver um papel significativo na determinação da posição do custo relativo ou da diferenciação.

Nessa perspectiva, a utilização de sistemas de informação e tecnologias avançadas de produção (Advanced Manufacturing Technologies - AMTs), estas últimas entendidas como hardwares e softwares avançados de manufatura, é fundamental para capacitar os processos empresariais para a customização em massa (Barrenechea, 2010; Duray et al., 2000; Hart, 1995; Kotha, 1995, 1996; Lau, 
1995; Piller \& Kumar, 2006; Quintela \& Costa, 1997; Ross, 1996; Rudy, 2002; Salvador, De Holan, \& Piller, 2009; Silveira, Borenstein, \& Fogliatto, 2001; Zerenler \& Ozilhan, 2007; Zipkin, 2001).

Depreende-se, por meio da revisão da literatura, que, para a construção de um eficiente sistema de customização em massa, deve-se analisar como a tecnologia pode dar suporte para o sucesso de, pelo menos, cinco elementos: interação e acompanhamento do cliente; flexibilidade do sistema produtivo; maximização do projeto colaborativo; integração entre os elos da cadeia de suprimentos; integração entre as atividades da cadeia de valor responsáveis pela customização.

No primeiro caso, quanto mais a empresa permitir que o cliente participe do desenvolvimento de seu próprio produto, maior a probabilidade de ele ficar satisfeito com o desempenho geral do produto final. Assim, a empresa precisa dispor de uma forma conveniente e ao mesmo tempo acurada de o cliente especificar exatamente aquilo de que necessita. Isso implica a necessidade de empreender esforços para prover mecanismos de interação que possibilitem a obtenção de informações específicas do cliente.

A esse respeito, Zipkin (2001) afirma que existem muitos tipos de informações requeridas para sistemas de customização em massa que podem ser perfeitamente tratadas de forma rápida e econômica, por meio do uso do computador e da internet, podendo ainda ser auxiliadas por sistemas de gerenciamento do relacionamento com o cliente (Customer Relationship Management - CRM). Corroborando esse raciocínio, resultados de estudo empreendido no setor nacional de telecomunicações destacaram a relevância do uso da tecnologia de CRM como ferramenta estratégica para viabilizar o deslocamento da produção em massa para a customização em massa (Prieto, Laurindo, \& Carvalho, 2007).

Ademais, o uso estratégico da TI (particularmente a internet) tem propiciado os meios necessários para a aplicação de estratégias de customização em massa em setores inusitados, como é o caso do setor de eletrodomésticos. No Brasil, uma recente pesquisa demonstrou que a adoção dessa estratégia em uma empresa líder na fabricação de produtos da linha branca (geladeiras), a qual decidiu comercializar exclusivamente pela internet uma linha de seus produtos, contribuiu para atrair clientes para um relacionamento mais próximo, criar valor para esses clientes, reforçar os valores próprios da marca e manter a competitividade (Zilber \& Nohara, 2009).

Sob o enfoque do acompanhamento do cliente, os sistemas de informações permitem que as organizações possam analisar seus consumidores por meio de modelos, gostos e preferências. Como resultado desses esforços, torna-se possível o lançamento de campanhas mais eficientes de comunicação e marketing para mercados-alvo específicos. Nessa perspectiva, o uso de bancos de dados eletrônicos tem ajudado as empresas a acompanhar a trajetória de numerosas interações 
individuais com seus clientes, permitindo examinar todo o seu histórico de transações com eles, registrar suas particularidades, traçar um perfil de consumo e entender como agregam e obtêm valor da empresa (Peppers \& Rogers, 1997).

No setor de construção civil, por exemplo, empresas fazem uso de sistemas de informação para dar o suporte necessário ao monitoramento das percepções dos clientes nas várias fases do relacionamento (da prospecção ao pós-venda), de modo a servir de insumo para novos lançamentos e ações de melhoria, além de permitir identificar as necessidades de customização e registrar os problemas que requerem manutenção (Machado \& Moraes, 2008).

O segundo elemento, flexibilidade, consiste em permitir que o sistema de produção tenha a capacidade de atender, rápida e economicamente, às necessidades individuais dos clientes. Nesse contexto, a importância de se adotar Sistemas Flexíveis de Manufatura (Flexible Manufacturing Systems - FMS) nas operações industriais tem se acentuado e a utilização desses sistemas pode contribuir para o sucesso da customização em massa (Berman, 2002; Duray et al., 2000; Lau, 1995; Pine II, Victor, \& Boynton; 1993; Zerenler \& Ozilhan, 2007).

Os FMS podem ser conceituados como um agrupamento de máquinas, interligadas por um sistema automatizado de transporte e transferência de materiais, integrados por um sistema central de controle por computador, capaz de produzir uma determinada variedade de tipos de produtos/peças (Caulliraux, Marietto, \& Coca-Balta, 1992; Gaither \& Frazier, 2001; Kusiak, 1985).

Para sua operacionalização, normalmente são necessários investimentos não só em automação, mas também em capacitação de pessoal e controles mais precisos dos processos. O papel da tecnologia na integração, gerenciamento e operacionalização das tarefas que se relacionam aos sistemas de manufatura, no entanto, é fundamental.

Nesse sentido, a utilização adequada de tecnologias avançadas de produção, como Projeto Auxiliado por Computador (Computer Aided Design - CAD), Manufatura Auxiliada por Computador (Computer Aided Manufacturing - CAM), Garantia da Qualidade Auxiliada por Computador (Computer Aided Quality Assurance - CAQ) e Planejamento do Processo Auxiliado por Computador (Computer Aided Process Planning - CAPP) se mostram importantes para suportar as atividades envolvidas no processo de customização em massa.

Relatos de pesquisa, recentemente divulgados, demonstraram que a adoção de tecnologias CAD 3D/CAM tem propiciado a aplicação da customização em massa em áreas pouco exploradas, tais como a fabricação de implantes dentários e ortopédicos, reduzindo o tempo e os custos associados à melhoria da qualidade de vida dos pacientes (Eyers \& Dotchev, 2010). 
Ademais, softwares e hardwares que envolvam Engenharia Auxiliada por Computador (Computer Aided Engineering - CAE), Planejamento das Necessidades de Material (Material Requirements Planning - MRP), Planejamento dos Recursos da Empresa (Enterprise Resource Planning - ERP), Manufatura Integrada por Computador (Computer Integrated Manufacturing CIM), robôs, demais equipamentos e sistemas automatizados de produção também constituem importantes suportes para a conquista de vantagens competitivas.

O terceiro elemento, destacado por Hart (1995); Kotha (1995); Lau (1995); Pine II et al. (1993); Ross (1996) e Rudy (2002), envolve dar aos membros do time de projetos (os quais devem ser compostos por profissionais de diferentes áreas funcionais, podendo estar localizados em regiões geográficas distintas, pertencentes à mesma empresa ou de empresas diferentes) ferramentas que permitam trabalhar efetivamente juntos (de forma cooperativa), de modo a minimizar o tempo envolvido durante as fases do trabalho e reduzir custos.

Nesse sentido, responder eficientemente às exigências do mercado, em termos de novos produtos, exige um esforço conjunto das equipes de produção, pesquisa e desenvolvimento, marketing e finanças, além da integração entre o planejamento do processo e do projeto do produto, de forma a reduzir o tempo para colocação do produto no mercado.

Assim, uma vez que o principal insumo numa empresa de customização em massa é a informação, as organizações precisarão dar atenção especial ao planejamento dos seus sistemas de informações, de modo a alcançarem maior flexibilidade em seus bancos de dados, redes de comunicação e sistemas CAD/CAM que compõem sua infraestrutura (Byrd, 2001; Lau, 1995).

O quarto elemento consiste em selecionar a tecnologia que potencialize a integração entre os elos da cadeia de suprimentos. Nesse sentido, sistemas de informação podem ser utilizados estrategicamente para a formação de parcerias, que cruzam seus sistemas para criar sinergias únicas. Dessa forma, as empresas podem juntar forças para compartilhar informações, ajudando a atingir novos consumidores, criar novas oportunidades para vendas e produtos-alvo, podendo também compartilhar os investimentos em hardware e software.

Ademais, as empresas estão cada vez mais utilizando a transmissão eletrônica de dados, por meio de ferramentas de intercâmbio eletrônico de dados (Electronic Data Interchange - EDI) e internet, para tornarem mais eficientes suas operações, conseguindo reduzir custos com estoques; diminuir o lead time de reposição e sincronizar pedidos (Silva \& Fischmann, 2000), habilitando-as a implementar técnicas avançadas de logística, como just in time e milk run (o qual envolve a coleta programada de insumos realizada pela empresa cliente junto a seus fornecedores), por exemplo. 
Por fim, um dos aspectos críticos para a eficiente execução da Customização em Massa consiste em como utilizar a TI para conectar as diferentes atividades que participarão do processo de customização e que compõem a cadeia de valor da empresa. Caso haja êxito nesse desafio, obter-se-á uma produção flexível e eficiente, capaz de ofertar diferentes unidades de bens, atendendo aos requisitos individuais do cliente, sem comprometer a qualidade, custo ou tempo (Barrenechea, 2010). A amplitude de participação de cada atividade, por seu turno, definirá a extensão da customização e a estratégia a ser adotada (Lampel \& Mintzberg, 1996).

\section{PROCEDIMENTOS METODOLÓGICOS}

A estratégia de pesquisa selecionada foi a de estudo de casos de múltiplos.

[...] os estudos de caso representam a estratégia preferida quando se colocam questões do tipo 'como' e 'por que', quando o pesquisador tem pouco controle sobre os eventos e quando o foco se concentra em fenômenos contemporâneos inseridos em algum contexto da vida real (Yin, 2007, p. 19).

O estudo de casos múltiplos (ou coletivos) permite prover insights sobre um determinado assunto ou mesmo refinar uma teoria de forma mais consistente (Stake, 1994). O resultado da replicação de casos individuais, por sua vez, contribui sobremaneira para a validade externa ou generalização das suas descobertas (Merriam, 1998).

No intuito de proporcionar uma visão ampla do fenômeno em estudo, foram selecionadas e pesquisadas sete empresas (Quadro 1) abrangendo diferentes divisões de atividades econômicas, conforme Classificação Nacional de Atividades Econômicas (CNAE) elaborada pelo Instituto Brasileiro de Geografia e Estatística (Instituto Brasileiro de Geografia e Estatítica [IBGE], 2004). O número de empresas decorreu da disponibilidade de acesso, recursos e tempo disponível (Rowley, 2002).

Revista de Administração e Inovação, São Paulo, v. 8, n. 2, p.190-215, abr./jun. 2011 
Tecnologia de informação e customização em massa: evidências na indústria de transformação

\begin{tabular}{|c|l|l|}
\hline Empresa & \multicolumn{1}{|c|}{ Atividade Econômica } & \multicolumn{1}{|c|}{ Cargo dos entrevistados } \\
\hline 1 & $\begin{array}{l}\text { Fabricação e montagem de veículos } \\
\text { automotores, reboques e carrocerias }\end{array}$ & $\begin{array}{l}\text { Engenheiro de Produto; Especialista de } \\
\text { Mercado }\end{array}$ \\
\hline 2 & $\begin{array}{l}\text { Fabricação de máquinas, aparelhos e } \\
\text { materiais elétricos }\end{array}$ & $\begin{array}{l}\text { Diretor de Engenharia; Gerente de } \\
\text { Engenharia Industrial; Gerente de Motores } \\
\text { Industriais }\end{array}$ \\
\hline 3 & $\begin{array}{l}\text { Confecção de artigos do vestuário e } \\
\text { acessórios }\end{array}$ & Vice-Presidente; Diretor Industrial \\
\hline 4 & $\begin{array}{l}\text { Confecção de artigos do vestuário e } \\
\text { acessórios }\end{array}$ & Diretor Executivo \\
\hline 5 & $\begin{array}{l}\text { Preparação de couros e fabricação de } \\
\text { artefatos de couro, artigos de viagem e } \\
\text { calçados }\end{array}$ & $\begin{array}{l}\text { Gerente Industrial; Gerente de } \\
\text { Controladoria }\end{array}$ \\
\hline 6 & Fabricação de produtos químicos & Diretor Presidente; Diretor Industrial \\
\hline 7 & Fabricação de móveis e indústrias diversas & $\begin{array}{l}\text { Gerente Industrial; Responsável pela área } \\
\text { de Desenvolvimento do Produto; Analista } \\
\text { técnico }\end{array}$ \\
\hline
\end{tabular}

Quadro 1- Empresas Pesquisadas.

Fonte: Elaborado pelos autores.

Dois critérios foram adotados para seleção dos casos: 1- pertencer à indústria de transformação; 2- as empresas já deveriam contemplar, em suas respectivas estratégias, ações associadas à customização dos seus respectivos produtos e serviços. Além disso, foram mantidos contatos com vinte acadêmicos (de diferentes instituições de ensino e pesquisa localizadas no país) envolvidos com estudos sobre estratégia e desempenho empresariais, para que pudessem sugerir possíveis empresas a serem estudadas.

Para obtenção dos dados necessários, os sujeitos-alvo da pesquisa foram, em sua maioria, executivos pertencentes a áreas funcionais usuárias da tecnologia de informação nas empresas selecionadas, totalizando 15 entrevistados. O número de entrevistados decorreu da disponibilidade de acesso.

\subsection{INSTRUMENTOS DE COLETA DE DADOS}

Para a coleta dos dados secundários, foi realizada uma pesquisa bibliográfica em livros, monografias, dissertações, teses, artigos dispostos em anais de congressos e encontros, revistas e jornais nacionais e internacionais das áreas de administração, economia e engenharia de produção. Para dar o suporte necessário à obtenção de artigos acadêmicos internacionais, foram utilizadas as bases de dados EBSCO e ProQuest.

Revista de Administração e Inovação, São Paulo, v. 8, n. 2, p.190-215, abr./jun. 2011 
Para a coleta de dados primários foram utilizadas, principalmente, observações diretas e entrevistas semiestruturadas (Merriam, 1998). O uso da observação permitiu que os pesquisadores percebessem os fatos diretamente, sem qualquer intermediação, reduzindo a subjetividade e permitindo coletar evidências complementares sobre o fenômeno estudado.

Para execução das entrevistas, foi elaborado um roteiro de tópicos, composto por um conjunto de questões abertas, no qual o pesquisador teve a liberdade de sondar razões e motivos que sustentassem determinadas decisões por parte da empresa.

Concluídos os procedimentos de planejamento da pesquisa, foram realizados, inicialmente, contatos por telefone e por e-mail com representantes das empresas-alvo da investigação. Em seguida, as questões centrais envolvidas no roteiro de entrevista, juntamente com uma carta de apresentação, foram enviados, por e-mail, aos respondentes da pesquisa.

O envio das questões centrais constantes no roteiro de entrevista, por sua vez, teve dois objetivos. Em primeiro lugar, permitir que a empresa selecionasse os profissionais mais adequados para responder aos questionamentos. O segundo propósito implicou otimizar o tempo despendido durante a realização da entrevista, uma vez que o entrevistado poderia colher previamente informações, documentos e registros relacionados às questões elaboradas.

Para otimizar os procedimentos, e com a devida permissão dos entrevistados, todas as entrevistas foram gravadas para posterior transcrição. Ao final de cada entrevista, foi solicitado que o entrevistado respondesse a um pequeno questionário com onze questões que contemplavam informações básicas sobre a empresa e sua atividade como profissional.

\subsection{ANÁLISE DOS DADOS}

Em estudo de casos múltiplos, há dois estágios de análise: a análise individual dos casos e a análise cruzada dos casos (Merriam, 1998; Yin, 2007). A análise dos dados foi realizada em seis fases. A primeira fase pode ser compreendida como uma pré-análise na qual, concomitantemente à observação in loco e à transcrição das gravações das entrevistas, os pesquisadores adicionaram suas impressões e reflexões.

Em seguida, numa segunda fase, foi realizada uma análise individual dos casos. Essa tarefa permitiu não só que os pesquisadores se familiarizassem com as características operacionais específicas de cada empresa, mas também contribuiu para a identificação de padrões emergentes em cada caso (Eisenhardt, 1989).

Revista de Administração e Inovação, São Paulo, v. 8, n. 2, p.190-215, abr./jun. 2011 
Numa terceira fase, foram elaborados relatórios distintos, por empresa. Cada relatório foi enviado (por e-mail) para os respectivos representantes de cada empresa pesquisada. Por meio de uma carta, anexada a cada relatório, foi solicitado que se fizesse uma avaliação a respeito da análise dos dados desenvolvida, com o objetivo de verificar a conformidade dos resultados à realidade observada. Pretendeu-se, por meio desse procedimento, contribuir para o alcance da validade interna dos dados.

De posse dos comentários realizados pelos entrevistados, os pesquisadores, numa quarta fase, revisaram a análise previamente realizada, de modo a torná-la o mais realista possível. Na quinta fase, as descobertas de cada caso foram comparadas entre si, de modo a identificar a existência de similaridades e contradições de respostas entre entrevistados, seguindo a lógica de replicação para casos múltiplos. Esses esforços estiveram vinculados à obtenção da validade externa dos resultados. Os resultados, na sexta e última fase, foram analisados à luz da teoria que fundamenta o assunto em enfoque.

\section{ANÁLISE INDIVIDUAL DOS CASOS}

\subsection{EMPRESA 1}

A empresa, objeto do estudo, possui 55 anos de atividades e detém cerca de $42 \%$ do mercado brasileiro do segmento de reboques e semirreboques. Dentre os produtos fabricados, destacam-se as carrocerias do tipo: basculante, canavieiro, carga seca, silos, tanques, transporte de bebidas, graneleiras (responsável por $65 \%$ da produção), furgões, carrega tudo, frigoríficos, porta contêineres e sider. A customização pode ocorrer em três estágios distintos: projeto (novos desenvolvimentos de produtos), fabricação (adequação do projeto) e montagem (customização planejada).

A adoção de tecnologia de informação (CAD, CAE, robôs, MRP, ERP e o software configurador de produto) representa um dos principais elementos para viabilizar a customização. A empresa utiliza a tecnologia CAD em três dimensões (CAD 3D). Isso agiliza os procedimentos de adequação de projeto, pois as alterações realizadas em uma peça são refletidas em todos os locais onde essa peça se insere. Quando se utilizam apenas duas dimensões, como acontece na maioria das empresas, é requerido um tempo maior para atualizar as modificações nos diferentes desenhos onde a alteração de uma peça era exigida. A esse respeito, comenta o Engenheiro de Produto: Há três anos migramos do CAD em duas dimensões (CAD 2D) para o CAD 3D. [...] Demorávamos, com o CAD 2D, um dia para desenvolvermos um novo componente e três semanas para atualizar as alterações nos

Revista de Administração e Inovação, São Paulo, v. 8, n. 2, p.190-215, abr./jun. 2011 
trinta chassis que utilizam este componente. No CAD 3D, todos os itens compostos por componentes que sofreram alteração são atualizados automaticamente.

Ademais, por meio do CAD 3D foi possível montar um banco de dados do projeto, no qual, caso se necessite realizar um desenho com determinadas especificações de comprimento, basta apenas entrar com as variáveis e o desenho é, então, gerado. A adoção do CAD 3D, por sua vez, também estimulou a implementação do CAE e sua integração com o software de desenvolvimento do projeto. Com isso, foi possível realizar análises estruturais do produto.

Os robôs, por sua vez, são utilizados nas linhas que apresentam grandes volumes de produção, a fim de aumentar a produtividade e melhorar a qualidade.

O plano operacional que estima a fabricação trimestral por família de produtos é decidido mensalmente pela diretoria e repassada para a área de Planejamento e Controle da Produção (PCP). Os dados são então incluídos no sistema MRP para avaliar a necessidade de recursos que será exigido para atender ao plano, e as informações são atualizadas mensalmente.

O plano de produção de itens de produtos finais, por sua vez, é gerado por meio do Plano Mestre de Produção e apresenta três níveis: todos os produtos; famílias de produtos; itens genéricos. Este último nível é composto por materiais que podem fazer parte de produtos diferentes pertencentes a uma mesma família. Esses itens genéricos estão integrados ao Configurador de Produto, o qual é um software que funciona tanto nas dependências do distribuidor quanto internamente à fábrica.

Neste último caso, ele funciona em conjunto com o MRP. A partir de uma série de perguntas e respostas, monta-se, por meio de uma programação lógica de estrutura de itens, o produto final. Módulos específicos do sistema, os quais são integrantes do software de gestão empresarial BAAN (ERP), geram ordens de compra e fabricação.

\subsection{EMPRESA 2}

Atualmente com 12 mil funcionários, a empresa é líder de motores elétricos na América Latina, figura entre os cinco maiores fabricantes do mundo e está presente em mais de 100 países nos cinco continentes. Em seus dez parques fabris (cinco localizados no Brasil, dois na Argentina, um no México, um em Portugal e um na China) a empresa controla todas as etapas de sua produção, desde a fundição e a estamparia de metal, até a esmaltação e a embalagem.

Os estágios em que ocorre a customização dependem do grupo de produtos que será comercializado. Caso seja necessário disponibilizar produtos especiais, a customização ocorre desde o projeto, quando a empresa participa junto com o cliente da concepção do projeto para fabricação do 
novo produto. Caso os pedidos possam ser atendidos por meio da combinação dos módulos de componentes padronizados dos produtos, a customização ocorre nos níveis de fabricação e montagem, utilizando como suporte para a operacionalização dessa tarefa um software Configurador de Produto.

Para alcançar o propósito de customização em massa, acredita-se que tenha que existir um sistema que permita armazenar e recuperar, rapidamente, os dados referentes às características das estruturas mecânica (principalmente em termos dimensionais) e elétrica já configuradas. Além disso, este sistema deve selecionar os itens componentes de um produto já existente, que apresentem similaridades com o pedido do cliente, de modo que se possa agregar as estruturas e componentes no produto a ser disponibilizado.

Destarte, não é só a geração do modelo e da estrutura do produto que é importante, mas também as formas de gerenciamento e controle dos componentes são fundamentais, explica o Gerente de Engenharia de Motores Industriais.

Quando se trata de motores especiais, do ponto de vista da engenharia, como se tem mais de 160 mil itens, é necessário que haja ferramentas de gerenciamento que permitam localizar itens previamente projetados e que são similares aos que o cliente deseja. Observa-se, pois, a necessidade da existência de sistemas de informações que agilizem o fluxo de informações entre o cliente, a área de vendas e a engenharia.

Assim, como afirma o Gerente de Engenharia de Motores Industriais, são empreendidos grandes esforços para o desenvolvimento de ferramentas de gerenciamento e geração do produto que integrem desde a área de vendas até a ferramentaria, de modo a reduzir o tempo e tornar o sistema produtivo mais flexível para atender às necessidades dos clientes. Apenas na área de engenharia, por exemplo, existem quatro pessoas trabalhando exclusivamente para alcançar esses objetivos, sob o suporte da equipe do Departamento de Sistemas de Informações (DSI).

Para se ter uma ideia do nível de utilização de sistemas de informação, a seguir, é discriminado o fluxo de informações desde o momento do pedido pela área de vendas até o produto se encontrar em produção.

O pessoal de vendas alimenta um sistema CRM (SASO - Sales Softwares), o qual dá o apoio na configuração dos dados do produto e informa se há necessidade de desenhos e criação de itens especiais. Este sistema se comunica com o software de gestão integrada BAAN, o qual gera o pedido do produto, ordem de produção ou a necessidade de estruturação de itens novos.

O BAAN, por sua vez, comunica-se com o sistema de gerenciamento de dados do produto (PDM - Product Data Management) que realiza uma pesquisa para identificar se o componente mecânico já existe. Caso não exista, são criados novos itens e novos desenhos (adotando também 
sistemas CAD) e realizado o detalhamento elétrico. Por fim, as estruturas completas do novo produto e as notas de operação são transferidas para o BAAN.

Assim, os principais sistemas são: CRM (SASO), BAAN, PDM e CAD.

\subsection{EMPRESA 3}

A empresa atua no mercado varejista de roupas masculinas e possui, aproximadamente, 500 funcionários distribuídos nas suas 16 lojas. Além disso, é detentora de uma fábrica que produz cerca de 150 mil peças/ano, possui $6.000 \mathrm{~m}^{2}$ de área construída, e apresenta, aproximadamente, 300 funcionários em seu quadro funcional.

A customização pode ocorrer em dois pontos distintos: o projeto e a partir da fabricação. $\mathrm{O}$ primeiro caso diz respeito à implementação de pedidos que não podem ser atendidos por meio dos modelos armazenados no banco de dados da empresa, necessitando o desenvolvimento de novas peças componentes e, muitas vezes, novos fornecedores. No segundo caso, a customização se inicia na fabricação, por meio de ajustes virtuais dos componentes padronizados (e arquivados em banco de dados) para atender às dimensões do cliente.

Para fins de customização, o uso da tecnologia de informação é fundamental. A utilização do CAD, integrado a um software de customização (importado da Espanha) específico para atividades desempenhadas e à programação dos equipamentos de corte, permite que se eleve a produtividade, reduza as perdas e seja possível obter escala, pois o tempo envolvido nas operações de desenho e corte de produtos diferenciados são reduzidos.

Sem a tecnologia de informação, seria muito difícil realizar, em curtos espaços de tempo, as modelagens para cada pedido individual, pois o número de partes componentes dos produtos é muito grande (para se ter uma ideia da gama de componentes, apenas um terno tem 47 componentes; calça e camisa apresentam, individualmente, 19 componentes).

Esse fato pode ser ilustrado por meio da seguinte comparação feita pelo Diretor Industrial: "[...] hoje, um modelista é capaz de fazer entre 35 e 40 produtos customizados por dia. Sem o software apropriado, talvez fosse apenas possivel fazer um modelo”.

Outra vantagem da adoção de tecnologia é o acompanhamento do cliente: no momento em que é feito o modelo personalizado, são armazenados os dados dos clientes, e a cada transação, é registrado seu histórico de compras e de modificações de medidas. Ademais, a agilidade na troca de informações entre modelos é essencial para aumentar a velocidade do processo produtivo e reduzir os custos.

Revista de Administração e Inovação, São Paulo, v. 8, n. 2, p.190-215, abr./jun. 2011 


\subsection{EMPRESA 4}

A empresa é a primeira camisaria virtual do Brasil em que é possível fabricar uma camisa a partir das medidas e desejos do cliente. São disponibilizadas, aproximadamente, 70 mil combinações possíveis. A empresa se responsabiliza pela fabricação, qualidade, prazo e atendimento às necessidades do consumidor, mas a tomada de medidas é de responsabilidade do cliente.

Caso seja solicitado um modelo que não conste no catálogo de opções da empresa, a customização se inicia no estágio de projeto, em que serão desenvolvidos novos gabaritos e adquiridos novos materiais. Já para pedidos que podem ser atendidos a partir das combinações de opções disponibilizadas, a customização ocorre no estágio de fabricação.

De acordo com o Diretor Executivo, a tecnologia foi o principal habilitador da customização em massa: [...] sem a internet seria impossível esta operação, porque ela permite não apenas a interação entre o chão de fábrica e o cliente, mas também permite reduzir o tempo para operacionalizar todas as atividades envolvidas no atendimento do pedido. Toda a tecnologia foi desenvolvida internamente, a partir de uma plataforma de e-commerce. É claro que poderia se dar por fax, mas seria necessário um tempo maior para digitar as informações no nosso sistema, armazenar dados, etc.

Dentro do modelo que se imagina para o futuro do negócio, a tecnologia é fundamental para viabilizar o projeto, por meio da integração de vários softwares: [...] hoje, existe no mercado uma cabine de bodyscanner que permite colher dados sobre as medidas e enviá-las para programas de $C A D$, que por sua vez está integrado às máquinas. Então, o objetivo tecnológico é alinhar plataformas tecnológicas. Outra importância da tecnologia está no armazenamento do pedido do cliente, permitir que ele altere medidas. Este último fator nós desempenhamos bem.

Assim, o diferencial está na maneira como se armazena essas medidas, como são recuperadas para fazer uma segunda camisa. [...] Porque senão você se transforma em um alfaiate, aquela pessoa que não conseguirá crescer, pois não dará conta da demanda. A customização em massa envolve fazer roupas sob medida para milhares de clientes cadastrados. Para fazer isto, só com tecnologia. Só com banco de dados, e suporte de hardware e software. Sem isto, não se consegue crescer.

Nessa perspectiva, a qualidade da informação faz a diferença, pois existem muitas variedades de medidas, estilos e componentes para cada opção realizada por um cliente. A medida de uma camisa social é diferente de uma camisa esporte, por exemplo. Dessa forma, a montagem do banco de dados é

Revista de Administração e Inovação, São Paulo, v. 8, n. 2, p.190-215, abr./jun. 2011 
uma tarefa complexa, pois ele tem que proporcionar o resgate das informações de maneira fácil e rápida.

\subsection{EMPRESA 5}

A empresa fabrica calçados tanto para o mercado interno quanto para o mercado externo. $\mathrm{O}$ volume total de fabricação de suas unidades fabris pode alcançar, em períodos de pico de demanda, aproximadamente, 60 mil pares de calçados/dia e empregar 2.500 pessoas. Atualmente, customiza-se cerca de $60 \%$ do volume de produtos fabricados.

A customização pode ocorrer em diferentes estágios da cadeia de valor. Para atender a pedidos que não estejam contemplados no catálogo de produtos e que necessitem alterar a estrutura do calçado, a customização se inicia na fase de projeto. Porém, quando há a possibilidade de atender às especificações individuais dos clientes por meio da gama de produtos padronizados, necessitando apenas realizar pequenas modificações nos calçados, sem, no entanto, alterar o projeto, a customização pode iniciar-se no estágio de fabricação, principalmente na costura do cabedal, prosseguindo até a montagem do produto, com a customização da palmilha interna, por exemplo.

Ademais, caso seja solicitado, pode-se agregar valor ao produto no estágio de etiquetagem (imediatamente anterior à distribuição), na medida em que são anexadas etiquetas de preços ou código de barras específicas dos clientes. A execução dessas tarefas permite que a empresa disponibilize serviços de customização mesmo a partir de produtos padronizados.

A customização é apoiada por um sistema CAD/CAM existente na área de corte, o qual permite reduzir o tempo e os custos envolvidos na fabricação de calçados personalizados, o que viabiliza a produção customizada em menores volumes. Ademais, utiliza-se o software MRP no intuito de prover o suporte para planejamento e controle da necessidade de materiais, bem como se investe em tecnologia de processos que permita aumentar a flexibilidade e velocidade de fabricação, além de reduzir os custos.

A fim de permitir o rápido fluxo de informações para todos os setores envolvidos, no intuito de que as pessoas reconheçam as especificações contidas nos pedidos e se organizem para implementálas, é utilizado um sistema de gestão empresarial da empresa SAP. Todavia, em virtude dos elevados custos de manutenção demandados, este sistema está sendo substituído por outro que exija custos menores.

Revista de Administração e Inovação, São Paulo, v. 8, n. 2, p.190-215, abr./jun. 2011 


\subsection{EMPRESA 6}

Fundada em 1962, a empresa possui duas unidades industriais, 480 funcionários e apresenta um mix de 2.500 produtos, envolvendo tintas, solventes, adesivos e aditivos. Líder em adesivos para calçados na América Latina e um dos maiores fabricantes de tintas do país, a empresa tem volume de produção de, aproximadamente, 3 milhões de litros por mês e atua nos seguintes mercados: decorativo, metal-mecânico, moveleiro, calçados e couros.

A fabricação está focada tanto em produtos para estoque, oferecidos de forma padronizada no mercado, quanto produtos sob encomenda, atendendo às especificações dos clientes, sendo que $70 \%$ do faturamento são decorrentes da comercialização de produtos customizados.

A customização pode ocorrer em dois estágios: projeto e fabricação. O primeiro caso corresponde aos pedidos que exijam o desenvolvimento de novas fórmulas, as quais não se encontram previamente arquivadas em um banco de dados. Quando o pedido pode ser atendido por meio da postergação da manufatura e do compartilhamento de componentes padronizados, a customização ocorre a partir da fabricação.

O setor no qual a empresa encontra-se inserida não é caracterizado por rápidas mudanças tecnológicas, levando entre cinco e dez anos para a introdução de novos processos e produtos. Todavia, as necessidades dos clientes são bastante mutáveis, exigindo melhoria contínua dos processos para aumentar a agilidade no atendimento aos pedidos. Nesse sentido, os maiores recursos são destinados para o setor de tecnologia, no intuito de identificar oportunidades de melhoria nos processos produtivos.

Para agilizar o fluxo de informações, a empresa investiu em um software de gestão integrada (BAAN). A existência de bancos de dados com bibliotecas virtuais de mais de 15 mil fórmulas de produtos, por sua vez, permite agilizar a busca por características que mais se aproximam das variáveis do pedido solicitado pelo cliente, resultando em aumento da velocidade e redução da complexidade de fabricação.

Nas lojas de varejo, são disponibilizados softwares que interagem com as máquinas tintométricas, permitindo dosar as quantidades de corantes que compõem as fórmulas que permitem elaborar a cor e o volume de tinta desejada pelo consumidor.

O sistema de PCP, por seu turno, é integrado com o sistema dos clientes, de modo que estes enviam seus pedidos automaticamente para o setor produtivo, reduzindo os tempos envolvidos para o atendimento das suas necessidades.

Revista de Administração e Inovação, São Paulo, v. 8, n. 2, p.190-215, abr./jun. 2011 


\subsection{EMPRESA 7}

A empresa é especializada na produção de móveis modulares residenciais, estando no mercado há 66 anos. Voltada, principalmente, para o mercado interno, é líder no segmento em que atua. A empresa está instalada em um moderno parque fabril de $54.000 \mathrm{~m}^{2}$, o que a eleva a uma das maiores e mais avançadas fábricas de móveis da América Latina. Possui 445 funcionários e apresenta uma produção de 25 mil volumes/dia.

As atividades de customização iniciam-se nas lojas exclusivas da fábrica. Para apoiar essa tarefa é utilizado um software (Promob) que, automaticamente, lista todos os módulos, peças e acessórios gerando assim o pedido. Dentro das instalações fabris, existem dois pontos onde ocorre a customização dos produtos: fabricação de tampos e prateleiras lineares, e montagem de peças modulares. No primeiro caso, as peças são fabricadas de acordo com as dimensões exigidas pelos clientes, necessitando, para isso, de atividades de corte diferenciadas. O segundo caso diz respeito à montagem por meio da combinação de módulos padronizados, os quais são intercambiáveis entre os diferentes modelos oferecidos no mercado.

Para aumentar a flexibilidade e a velocidade, reduzir custos unitários e problemas associados às falhas da qualidade do produto, o processo é altamente automatizado. O transporte de materiais entre os equipamentos, por exemplo, também é automático. Como consequência da automação, poucos empregados são necessários na operação.

Sob a perspectiva da fabricação de materiais não lineares (peças de canto, curvas, peças que exigem um trabalho manual, com maior valor agregado), a adoção do processo automatizado e integrado mediante sistemas de informação permite que se obtenha a flexibilidade necessária para atender a diferentes pedidos dos clientes. A esse respeito, $10 \%$ dos equipamentos são flexíveis, facilitando que o atendimento a diferentes especificidades ocorra no menor tempo possível. É um número ainda pequeno, mas há previsões de maiores investimentos para a fábrica flexível.

Independentemente da cor ou do tamanho que o mercado exige, o PCP faz uma programação de modo a otimizar o processo e a velocidade das células de produção. Para dar o suporte às operações de manufatura, além de permitir a integração entre as demais áreas da empresa, investiu-se na aquisição de um software de gestão empresarial (EMS), o qual, por meio do módulo de manufatura, provê o suporte para o planejamento e controle de materiais. 


\section{ANÁLISE CRUZADA DOS CASOS}

A análise dos casos selecionados permitiu constatar que o uso da TI nos processos das empresas que customizam seus produtos em massa para os clientes não se dá de maneira uniforme. Apesar de a TI ser, de maneira geral, considerada um importante habilitador para o sucesso da estratégia de customização em massa, seu grau de utilização depende, principalmente, do estágio na cadeia de valor onde ocorre a customização e do modelo adotado para venda dos produtos e interação com os clientes.

Apesar de certos autores terem destacado o papel da TI na integração entre as diferentes atividades da cadeia de valor (Barrenechea, 2010) e para interação com o cliente (Salvador et al., 2009; Zilber; Nohara, 2009), as descobertas da presente pesquisa, no que toca aos condicionantes do grau de utilização da TI nos processos de customização em massa, não parecem ter sido devidamente contemplados pela literatura pesquisada.

Como se pode observar, no Quadro 2, as empresas pesquisadas executam atividades associadas à customização dos seus produtos em diferentes estágios da cadeia de valor, destacando-se a fabricação como o estágio mais comumente utilizado em prol deste objetivo.

\begin{tabular}{|c|c|c|c|}
\hline & \multicolumn{3}{|c|}{ Estágios onde pode ocorrer a customização } \\
\hline Empresa & Projeto & Fabricação & Montagem \\
\hline 1 & $\mathrm{X}$ & $\mathrm{X}$ & $\mathrm{X}$ \\
\hline 2 & $\mathrm{X}$ & $\mathrm{X}$ & $\mathrm{X}$ \\
\hline 3 & $\mathrm{X}$ & $\mathrm{X}$ & \\
\hline 4 & $\mathrm{X}$ & $\mathrm{X}$ & \\
\hline 5 & $\mathrm{X}$ & $\mathrm{X}$ & $\mathrm{X}$ \\
\hline 6 & $\mathrm{X}$ & $\mathrm{X}$ & \\
\hline 7 & & $\mathrm{X}$ & $\mathrm{X}$ \\
\hline
\end{tabular}

Quadro 2- Estágios onde pode ocorrer a customização.

Fonte: Elaborado pelos autores.

No caso de empresas que lidam com a customização desde o projeto do produto, desenvolvendo novos produtos ou adequando suas especificações para atender às necessidades individuais dos clientes, observa-se o uso intensivo de sistemas CAD. Tais sistemas, em conformidade com o que apregoam Heizer e Render (2001), aumentam a produtividade dos projetistas e reduzem custos operacionais, na medida em que os parâmetros dos projetos podem ser manipulados, analisados e modificados mais rapidamente, tornando possível a revisão de numerosas opções antes que as decisões finais sejam tomadas.

Revista de Administração e Inovação, São Paulo, v. 8, n. 2, p.190-215, abr./jun. 2011 
Além disso, corroborando as afirmações de Gaither e Frazier (2001), o CAD permite melhorar a qualidade dos projetos e criar um banco de dados de manufatura. A importância da aplicação de sistemas CAD nas indústrias automobilística (empresa 1), mecânica (empresa 2), vestuário (empresas 3 e 4) e calçados (empresa 5) foi também enfatizada por Dantas, Gonçalves e Carvalho (1995).

A utilização de máquinas CNC, por seu turno, foi mencionada, principalmente, pelas empresas que necessitam customizar os produtos na fase de fabricação. Entre os principais benefícios associados ao uso desta tecnologia, destaca-se a redução de perdas, o aumento da confiabilidade, produtividade, flexibilidade (por causa da redução dos tempos de setup) e qualidade do produto. Tais vantagens estão em consonância com o que foi divulgado por Heizer e Render (2001).

Ademais, em acordo com o que foi publicado por um conjunto de pesquisadores (tais como: Eyers \& Dotchev, 2010; Kotha, 1995, 1996; Silveira et al., 2001; Spira, 1993), constatou-se que a utilização integrada de CAD/CAM, em virtude da redução dos tempos e custos produtivos, tem contribuído para viabilizar a fabricação de produtos personalizados em grandes volumes.

Para os produtos que são customizados, essencialmente, no estágio de montagem, todavia, as tecnologias CAD e CAM não são consideradas fundamentais para o sucesso da estratégia de customização em massa. Resultado semelhante foi obtido por Duray et al. (2000), que identificaram uma baixa utilização de tais tecnologias em empresas categorizadas como montadoras. Neste caso, a existência de banco de dados, sistemas de informação e softwares MRP parece ser mais importante.

O uso de bancos de dados com bibliotecas virtuais de componentes já projetados de produtos permite armazenar e agilizar a busca por características que mais se aproximam das variáveis do pedido solicitado pelo cliente, contribuindo para o aumento da velocidade e redução da complexidade de fabricação.

Nesse sentido, para aquelas empresas que lidam com milhares de itens diferentes de produtos em seu processo produtivo, uma alternativa para otimizar as atividades de customização envolve a adoção de um software Configurador de Produto, o qual é utilizado pela Empresa 1, Empresa 2, e, de certa forma, pela Empresa 7 (por meio do software Promob). A utilização desse tipo de tecnologia no suporte ao processo de customização em massa não foi abordada pela literatura pesquisada.

Recuperar rapidamente os dados referentes às características de produtos já configurados, contudo, não é o suficiente para garantir o bom desempenho do sistema produtivo. Para isso, também se faz necessário o uso de ferramentas para gerenciamento e controle de informações, conforme destacado pelos gestores da Empresa 2.

Uma vez que as atividades de customização apenas se iniciam depois de recebido o pedido do cliente, o emprego de sistemas de informações flexíveis e que possibilitem a rápida integração entre o 
setor de vendas e as demais áreas envolvidas com a customização dos produtos na empresa é fundamental.

Nesse sentido, o investimento em sistemas informatizados de gestão empresarial tem permitido agilizar o fluxo de informações para rápida tomada de decisões, sendo adotados pelas seguintes empresas: Empresa 1, Empresa 2, Empresa 5, Empresa 6 e Empresa 7. A importância da adoção de sistemas de informação é corroborada por vários estudiosos sobre o tema da customização em massa (destacando-se: Barrenechea, 2010; Byrd, 2001; Lau, 1995; Machado \& Moraes, 2008; Piller \& Kumar, 2006; Prieto et al., 2007; Ross, 1996; Salvador et al., 2009; Silveira et al., 2001).

Diante do grande volume de materiais, suprimentos e componentes que fazem parte do sistema produtivo, instabilidade da demanda, complexidade das estruturas dos produtos disponibilizados, e em razão da velocidade que as empresas necessitam para reagir às mudanças, certas empresas (Empresa 1, Empresa 2, Empresa 5, Empresa 6 e Empresa 7) utilizam o software MRP, a fim de prover o suporte para o planejamento e controle das necessidades de materiais. A aplicação do MRP em sistemas de manufatura que apresentam as características supracitadas é defendida por Davis, Aquilano e Chase (2001).

Por fim, apesar da relevância da utilização da internet como importante tecnologia habilitadora da estratégia de customização em massa (Piller \& Kumar, 2006; Zipkin, 2001), seu uso foi apenas destacado pela Empresa 4, que a adota para interagir diretamente com seus clientes.

\section{CONCLUSÕES}

O objetivo deste artigo foi analisar como a tecnologia de informação está sendo utilizada para habilitar a adoção da customização em massa. Para isso, foram realizados estudos de casos em sete empresas pertencentes a diferentes setores da indústria de transformação. Observações diretas e entrevistas semiestruturadas foram adotadas como técnicas para coleta de dados. A análise de dados ocorreu em dois estágios: análise individual e análise cruzada dos casos.

A análise dos dados permitiu concluir, a exemplo do que foi observado na literatura, que a interação e o acompanhamento do cliente, a busca pela flexibilidade nos processos produtivos, a maximização do projeto colaborativo, a integração entre as atividades da cadeia de valor e, em menor grau de utilização, a integração entre os elos da cadeia de suprimentos, são elementos suportados pela tecnologia de informação para a execução da customização em massa.

Revista de Administração e Inovação, São Paulo, v. 8, n. 2, p.190-215, abr./jun. 2011 
A extensão da customização, ou seja, o conjunto de estágios da cadeia de valor nos quais ocorrem as atividades de customização do produto ou do serviço por parte da empresa, influencia a decisão a respeito de quais tecnologias devem ser adotadas para os propósitos da customização em massa.

Ademais, para as empresas que oferecem uma extensa variedade de alternativas de customização para o mercado e lidam com uma grande quantidade e diversidade de itens em seu processo produtivo, a utilização de um software Configurador de Produto contribui, sobremaneira, para aumentar a eficiência da estratégia de customização em massa.

As principais vantagens apregoadas ao uso da tecnologia de informação pelas empresas pesquisadas dizem respeito ao aumento da produtividade, velocidade, confiabilidade e flexibilidade, redução de tempos e custos produtivos, melhoria da qualidade do produto, otimização do gerenciamento e controle de informações, agilidade do fluxo de informações, por meio da rápida interação entre as áreas, em particular o setor de vendas e as demais áreas envolvidas no processo de customização, suporte para o planejamento e controle da necessidade de materiais.

Como limitações da pesquisa, pode-se argumentar que, apesar dos esforços empreendidos em prol da sua validade interna, em virtude das restrições de acesso impostas aos pesquisadores em relação a documentos, registros e pessoas, não foi possível examinar determinadas evidências, bem como entrevistar um maior número de integrantes de diferentes áreas funcionais de cada empresa selecionada. Ainda, os dados coletados por meio de entrevistas sofreram, como usual, influência da percepção dos entrevistados sobre as questões elaboradas.

Como oportunidades para futuras pesquisas, sugerem-se: identificar e analisar as tecnologias de informação que estão sendo adotadas por empresas do setor de serviços; realizar estudos longitudinais, buscando identificar, sob a perspectiva da gestão tecnológica, as transformações ocorridas por empresas que iniciaram suas atividades adotando um sistema de produção em massa e migraram para um sistema de customização em massa; analisar as relações associativas entre a extensão da customização, nível tecnológico e o desempenho empresarial.

\section{REFERÊNCIAS}

Addis, M., \& Holbrook, M. B. (2001). On the conceptual link between mass customization and experiential consumption: an explosion of subjectivity. Journal of Consumer Behaviour, 1(1), 5067.

Revista de Administração e Inovação, São Paulo, v. 8, n. 2, p.190-215, abr./jun. 2011 
Barrenechea, O. L. (2010). An information technology suitability index for mass customization. Master Dissertation, University of Texas-Pan American, Texas.

Berman, B. (2002). Should your firm adopt a mass customization strategy? Business Horizons, 45(4), 51-60.

Byrd, T. A. (2001). Information technology: core competencies and sustained competitive advantage. Information Resources Management Journal, 14(2), 27-37.

Caulliraux, H. M., Marietto, M. G. B., \& Coca-Balta, A. G. (1992). Índices de medida de flexibilidade. Revista Produção, 2(2), 133-143.

Dantas, E. H. G. P., Gonçalves, E. L. Z., \& Carvalho, M. O. G. (1995). Tecnologias informáticas na implementação do CIM. In H. M. Caulliraux, \& L. S. S. Costa (Org), Manufatura integrada por computador: sistemas integrados de produção: estratégia, organização, tecnologia e recursos humanos (pp. 93-132). Rio de Janeiro: Campus.

Davis, M. M., Aquilano, N. J., \& Chase, R. B. (2001). Fundamentos da administração da produção (3a ed.). Porto Alegre: Bookman.

Duray, R. (2002). Mass customization origins: Mass or custom manufacturing?. International Journal of Operations \& Production Management, 22(3), 314-328.

Duray, R., Ward, P. T., Milligan, G. W., \& Berry, W. L. (2000). Approaches to mass customization: configurations and empirical validation. Journal of Operations Management, 18(6), 605-625.

Eisenhardt, K. M. (1989). Building theories from case study research. The Academy of Management Review, 14(4), 532-550.

Eyers, D., \& Dotchev, K. (2010). Technology review for mass customization using rapid manufacturing. Assembly Automation, 30(1), 39-46. 
Gaither, N., \& Frazier, G. (2001). Administração da produção e operações (8a ed.). São Paulo: Pioneira Thomson Learning.

Hart, C. W. L. (1995). Mass customization: conceptual underpinnings, opportunities and limits. International Journal of Service Industry Management, 6(2), 36-45.

Heizer, J., \& Render, B. (2001). Administração de operações: bens e serviços (5a ed.). Rio de Janeiro: LTC.

Instituto Brasileiro de Geografia e Estatística. (2004). Classificação nacional de atividades econômicas (2a ed.). Rio de Janeiro: IBGE.

Kotha, S. (1996). From mass production to mass customization: the case of the National Industry Bicycle Company of Japan. European Management Journal, 14(5), 442-450.

Kotha, S. (1995). Mass customization: implementing the emerging paradigm for competitive advantage. Strategic Management Journal, 16(1), 21-42.

Kusiak, A. (1985). Flexible manufacturing systems: a structural approach. International Journal Of Production Research, 23(6), 1057-1073.

Lampel, J., \& Mintzberg, H. (1996). Customizing customization. Sloan Management Review, 38(1), 21-29.

Lau, R. S. M. (1995). Mass customization: the next industrial revolution. Industrial Management, 37(5), 18-19.

Machado, A. G. C., \& Moraes, W. F. A. (2008). Customização em massa na construção civil. Revista Brasileira de Gestão de Negócios, 10(29), 347-364.

Merriam, S. B. (1998). Qualitative research and case study applications in education. San Francisco: Jossey-Bass. 
Peppers, D., \& Rogers, M. (1997). Empresa 1:1: instrumentos para competir na era da interatividade. Rio de Janeiro: Campus.

Piller, F., \& Kumar, A. (2006). For each, their own. Industrial Engineer, 38(9), 40-45.

Pine II, B. J., Victor, B., \& Boyton, A. C. (1993). Making mass customization work. Harvard Business Review, 71(5), 108-118.

Porter, M. E. (1991). Estratégia competitiva: técnicas para análise de indústrias e da concorrência (7a ed.). Rio de Janeiro: Campus.

Prieto, E., Laurindo, F. J. B., \& Carvalho, M. M. (2007). Alinhamento entre a estratégia do negócio e a gestão do relacionamento com o cliente: caso de uma empresa de telefonia. Produção On line, 7(2), $30-42$.

Qiang, T., Vonderembse, M. A., \& Ragu-Nathan, T. S., (2001). The impact of time-based manufacturing practices on mass customization and value to customer. Journal of Operations Management, 19(2), 201-217.

Qiang, T., Vonderembse, M. A., Ragu-Nathan, T. S., \& Ragu-Nathan, B. (2004). Measuring modularity-based manufacturing practices and their impact on mass customization capability: a customer-driven perspective. Decision Sciences, 35(2), 147-168.

Quintela, H. M., \& Costa, S. G. (1997). A informática e a mudança do paradigma competitivo. Conjuntura Econômica, 51(3), 34-38.

Ross, A. (1996). Selling uniqueness. Manufacturing Engineer, 75(6), 260-263.

Rowley, J. (2002). Using case studies in research. Management Research News, 25(1), 16-27.

Ruddy, M. (2002). Mass customization now closer then ever. Machine Design, 74(12), 59-61. 
Salvador, F., De Holan, P. M., \& Piller, F. (2009). Cracking the code of mass customization. Sloan Management Review, 50(3), 71-78.

Shewchuk, J. P., \& Moodie, C. L. (2000). Flexibility and manufacturing system design: an experimental investigation. International Journal of Production Research, 38(8), 1801-1822.

Silva, A. L., \& Fischmann, A. A. (2000). Inovação em canais de distribuição - da tecnologia de informação à gestão da cadeia de suprimentos [CD-ROM]. Anais do Encontro da Associação Nacional de Pós-Graduação e Pesquisa em Administração, 24. Rio de Janeiro: ANPAD.

Silveira, G., Borenstein, D., \& Fogliatto, F. S. (2001). Mass customization: literature review and research direction. International Journal of Production Economics, 72(1), 1-13.

Spira, J. S. (1993). Mass customization through training at Lutron Electronics. Planning Review, 21(4), 23-24.

Squire, B., Brown, S., Readman, J., \& Bessant, J. (2006). The impact of mass customisation on manufacturing trade-offs. Production and Operations Management, 15(1), 10-21.

Stake, R. E. (1994). Case studies. In N. K. Denzin, \& Y. S. Lincoln (Eds.), Handbook of qualitative research (pp. 236-247). London: Sage, 1994.

Yin, R. K. (2007). Estudos de caso: planejamento e métodos (D. Grassi, Trad.). (3a ed.). Porto Alegre: Bookman.

Zerenler, M., \& Ozilhan, D. (2007). Mass customization manufacturing (MCM): the drivers and concepts. Journal of American Academy of Business, 12(1), 262-268.

Zilber, S. N., \& Nohara, J. J. (2009). Mass customization and strategic benefits: a case study in Brazil. The Electronic Journal on Information Systems in Developing Countries, 36(5), 1-26.

Zipkin, P. (2001). The limits of mass customization. Sloan Management Review, 42(3), 81-87.

Revista de Administração e Inovação, São Paulo, v. 8, n. 2, p.190-215, abr./jun. 2011 


\title{
INFORMATION TECHNOLOGY AND MASS CUSTOMIZATION: EVIDENCES IN THE TRANSFORMATION INDUSTRY
}

\begin{abstract}
Mass customization strategy may be understood as a conjunction of plans that serve as reference for decision making in order to satisfy the necessities of individual clients, by means of a rapid disposition of goods and services at low prices and within large scales. The objective of this article is to analyze the information technology as it is being used to enable the adoption of mass customization. The research strategy adopted was a multiple-case study, which was carried out in seven companies belonging to different business of the transformation industry. Semi-structured interviews were implemented as the main technique for collecting data. The analysis of data took place in two phases: within-case analysis and cross-case analysis. The results verified that the use of the information technology in the processes of the businesses that perform mass customization of their products for their clients is not present in a uniform manner. Its degree of utilization primarily depends on the stage of the value chain where customization occurs and the model adopted for the sale of the products and client interaction. The research revealed interaction and the customer's accompaniment, the search for the flexibility in the productive processes, the optimization of the cooperative project and the integration among the links of the supply chain are elements supported by the information technology for the implementation of the mass customization.
\end{abstract}

Keywords: Customization; Information technology; Strategy.

Data do recebimento do artigo: 25/11/2011

Data do aceite de publicação: 03/03/2011 